\title{
Hybrid structures: innovative governance, judicial and sociological approaches
}

\section{Armando Aliu, Bekir Parlak \& Dorian Aliu}

Quality \& Quantity

Intemationsl Joumal of Methodology

$15 S N 0033517$

Qual Quant

DOI 10.1007/s11135-0149998-6

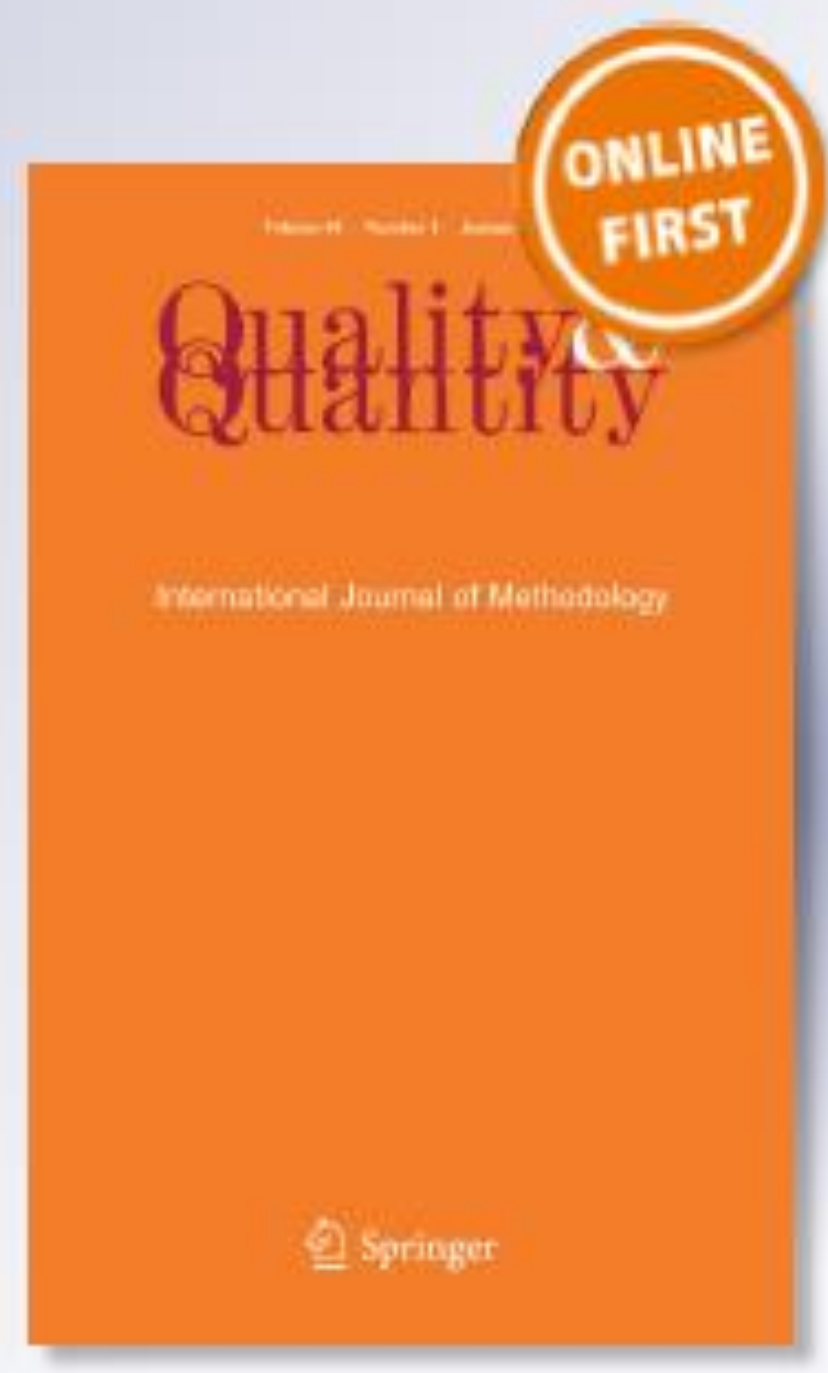

亚 Springer 


\title{
Hybrid structures: innovative governance, judicial and sociological approaches
}

\author{
Armando Aliu - Bekir Parlak • Dorian Aliu
}

() Springer Science+Business Media Dordrecht 2014

\begin{abstract}
The aim of this study is to examine the new trends in the hybridity research area and clarify the convergence of interests among state actors, private actors and civil society actors. Hybridity is perceived as a multidimensional phenomenon and new paradigm in various industries. The effective collaboration among public sector-private sector-civil society can be attained likelihood with taking into account regional governance and multilevel governance. Hybridity at global governance level covers decentration (supra: centralization and infra: decentralization; or politically/socioeconomically: quasi-decentralization and culturally: denationalization) which includes the nexus of voice (democratic participation) and entitlement (legal/social rights and duties). In this framework, this study explores state and non-state interactions at multiple levels and attempts to clarify how hybridization provides triple win solution for state actors, private actors and civil society actors related issues in realm of theory/praxis dichotomy. Through enhancing legitimacy and effectiveness of the activities and efforts of non-state actors in the framework of (quasi)indirect centralization
\end{abstract}

This paper was developed for the 4th International Conference on European Studies (ICES'13) that is organized by Epoka University in Tirana (Albania). Likewise, this article was written in the framework of the project that is entitled "The National Hybridity Project: Innovative Governance, Judicial and Sociological Approaches in Turkey (Project Grant No: KUAP(I)-2013/94)".

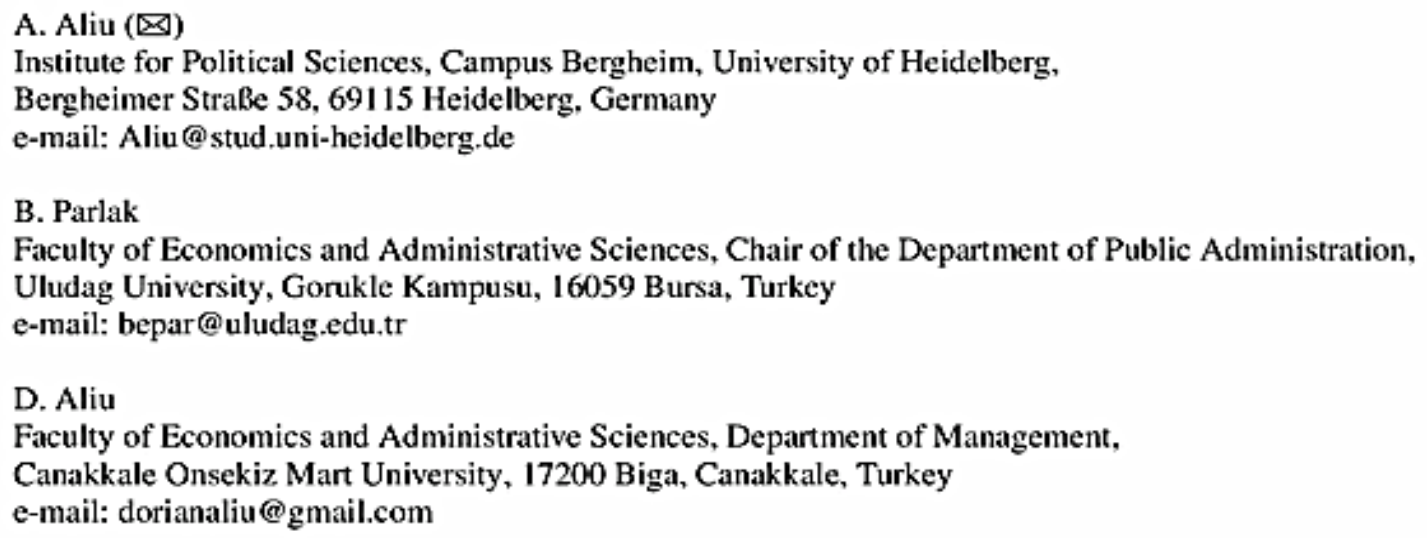


process, states ensure reciprocal understanding. In this study, constructivism was followed as paradigmatic research method.

Keywords Hybridity - Governance - Quasi-indirect centralization · Decentration

\section{Introduction}

Hybrid structures stand out as a new governance model of twenty first century. In fact, these structures which are established among government, market and civil society will enhance democratic participation and interaction in quasi-indirect centralization process (at supra level) and quasi-decentralization process (at infra level).

In some key researches, the development of multiscalar policies impacts on power relations has been argued for enrichment of the 'governance' notion (Church 2004; Beritelli et al. 2007; Baggio et al. 2010; Ruhanen et al. 2010). At the planning process of multilevel governance, in a quite high amount of studies has been attached considerable attention to the nexus among collaboration theory and community involvement through selection of key stakeholders (Bache and Chapman 2008; Cooper et al. 2009; Hultman and Hall 2012).

At the heart of the collaboration theory, there has been a shift from 'state-private partnership' (Jamal and Getz 1995; Page 2007; Bills 2010; Aliu 2011) to 'state-private-civil society collaboration' which is also accepted as 'hybridity'. Recently, many respected Scholars all around the world have pointed out the importance of hybridity notion and published many scientific works regarding hybrid model. In this context, this research mainly analyzes the reasons behind the purpose of such an increasing demand and illustrates why the usages and quotations of these notions (e.g. hybridity, hybrid model, and hybrid organizations) are keeping up (Anheier and Seibel 1990; Anheier 1991; Anheier and Toepler 1999; Evers 2005; Mückenberger 2008; Bills 2010; Aliu 2011; Herrmann 2011; Aliu 2012a, 2013).

In hybrid structure, the involvement of civil society to the state and private partnerships has become very crucial and even vital and moral for 'development of the third sector' (Bramwell and Lane 2011; Bramwell 201 1; Aliu 2012a,b, 2013). The involvement of non-state actors to central governmental works at national level and municipality works at local level in theory provides a quasi-decentralization process, however with effective hybridity it turns out to a quasi-indirect centralization process which enhances the image and development of states' authorities. Moreover, the institutions of the European Union have attained joint actions with non-state actors at various levels, provided that collaborations between state and non-state actors have been ranged in between multilevel governance perspectives and regional/local governance.

\section{Methodology}

In this study, constructivism was followed as paradigmatic research method. Constructivism, broadly conceived, is the thesis that knowledge cannot be a passive reflection of reality, but has to be more of an active construction by an agent. Although this view has its roots in the ideas of Kant, the term was first coined by Piaget to denote the process whereby an individual constructs its view of the world (Healy and Perry 2000; Moutinho 2012).

A contemporary dispute within constructivist social science is evidenced in the systems theory concept of autopoesis. Systems theory researchers, while acknowledging the constructivist activity of the mind, argue that science can offer something other than just scientific constructions. What emerges from the empirical process in systems theory is access to a set 


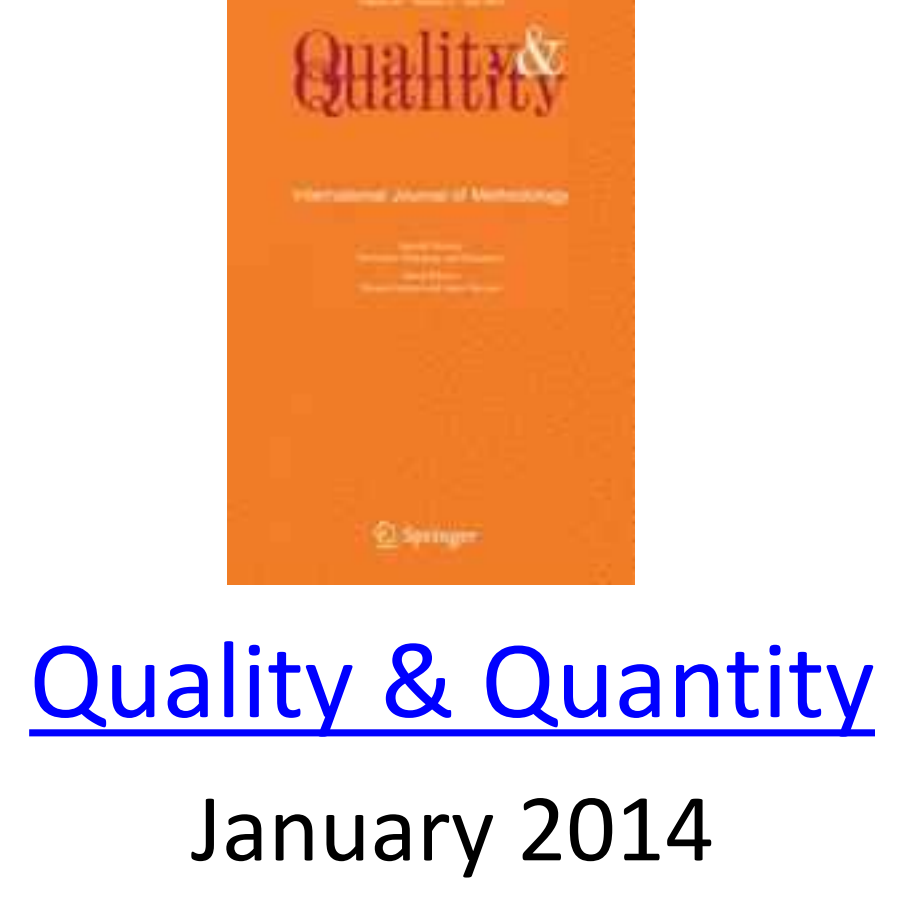

Hybrid structures: innovative governance, judicial and sociological approaches

Armando Aliu

Bekir Parlak

Dorian Aliu

... show all 3 hide

$\$ 39.95$ / €34.95 / £29.95 *

Purchase the article at a discount

Purchase now

Final gross prices may vary according to local VAT. https://checkout.springer.com/checkout/cart?3 